\section{Itsemurhatartunnan taikauskosta: The Moth Diaries (2011) ja 13 Reasons Why (2017) ${ }^{1}$}

\author{
Heidi S. Kosonen
}

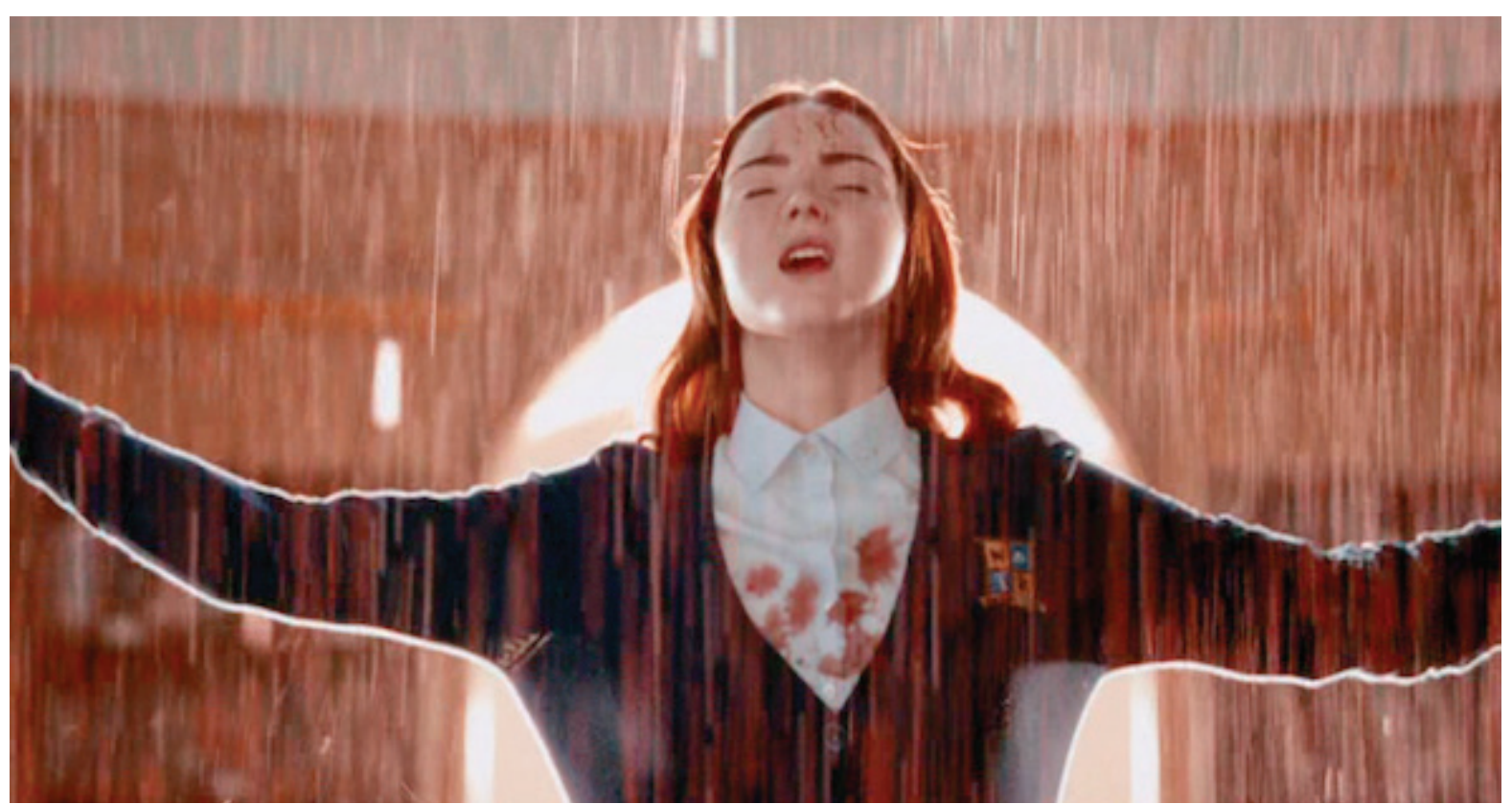

Kuva 1: Mary Harronin The Moth Diaries -elokuvassa (2011) vampyyri Ernessa (Lily Cole) houkuttelee teinityttö Rebeccaa itsemurhaan.
The Moth Diaries on kanadalaisen Mary Harronin vuonna 2011 ohjaama nuorten aikuisten kauhudraama, jossa vampyyri houkuttelee teinityttöä kuolemalla. Tyttö on toipumassa isänsä itsemurhasta, ja elokuvan keskeisessä kohtauksesta vampyyri yhyttää hänet koulun kirjastosta. "Sinun on tullut aika vapauttaa itsesi,"2 se kuiskaa ja viiltää ranteensa saaden yliluonnollisen veren valumaan tytön päälle. Kuoleman vetovoimaa edustava vampyyri ilmentää elokuvassa paitsi fiktiivisen nuoren pelkoja ja toiveita myös itsemurhatartuntana tunnettua ilmiötä. ${ }^{3}$ Omaehtoista kuolemaa on historiallisesti pelätty vaarallisena ja epideemisesti leviävänä kuolemana ${ }^{4}$ ja vanhemman itsemurha on määritelty yhdeksi tämän tartunnan lähteistä. $^{5}$

Perhepiirissä ja ikäryhmässä tapahtuvien itsemurhien lisäksi omaehtoisen kuoleman on nähty tarttuvan myös sen mediaesitysten myötä. Tässä merkityksessä itsemurhatartunta on esiintynyt esimerkiksi Brian Yorkeyn sovittaman 13 Reasons Why -sarjan ensimmäisen kauden vastaanotossa keväällä 2017. Nuorten suosioon noussut Netflix-sarja kohosi tällöin otsikoihin vaaralliseksi spektaakkeliksi määriteltynä ${ }^{6}$ ja kohtasi 
vaatimuksia sekä sarjan että siihen liittyneiden keskustelujen sensuurista. ${ }^{7}$ Kohu johti uudenlaisiin ikärajoituksiin, jotka suosittivat sarjan kieltämistä kaikilta sitä ilman aikuisen seuraa katsovilta alaikäisiltä. ${ }^{8}$ Sarjassa seurataan likeisesti teinitytön itsemurhaan päättyvää tarinaa, ja kerronnassaan sen pelättiin vaarallisella tavalla romantisoivan ja glorifioivan tätä tarttuvaksi miellettyä kuolemaa. Sosiologien, psykologien ja kansanterveystieteilijöiden 1970-luvulla nimeämää mediavälitteistä tartuntaa, Werther-efektiä, ${ }^{9}$ koskevassa keskustelussa näillä termeillä viitataan itsemurhaa kaunisteleviin ja sitä muilla tavoin ylentäviin esitysmuotoihin.

Artikkelissani lähestyn tätä mediavälitteistä tartuntaa pelkoon pohjaavana kuolemanhallintamekanismina tarkastelemalla näitä kahta populaarikulttuurin tapausta. Valitsemani tapausesimerkit ovat narratiiviensa, kohdeyleisöjensä ja itsemurhan visuaalisen kerrontansa osalta huomattavan samanlaiset ja myötäilevät monia valtavirtaistuneita konventioita. Huomionarvoista tapausesimerkeissä on näiden poikkeava vastaanotto, joka mahdollistaa 13 Reasons -sarjaan vaikuttaneen tartunnan kriittisen tarkastelun. Toisaalta, koska Moth kuvaa itsemurhahalua juuri vam- pyyrifiktion keinoin, se mahdollistaa tämän tartunnanmallin tarkastelun niistä peloista käsin, joita selittämättömäksi jääneisiin kuolemiin on historiallisesti liitetty. Mothin ikään kuin voisi väittää valottavan samoja pelkoja, joita 13 Reasons -sarjaa ympäröinyt kohu ilmentää.

Vaikka ajatus itsemurhatartunnasta on juurtunut syvälle julkiseen mielipiteeseen, sen vallitsevat selitysmallit eivät ole ongelmattomia. Niiden on muun muassa nähty rakentuvan aiheettomasti tunteisiin vetoavan tartunta-metaforan ympärille. ${ }^{10}$ Yksioikoisena kritisoitua Werther-efektiä taas ei ole onnistuttu vahvistamaan. ${ }^{11}$ Puutteistaan huolimatta se vaikuttaa median representaatioihin, ja siten vihjaa asemastaan biovallan rattaissa. Biovalta on yksilön ruumista kohtaan suuntautuvaa, normatiivista ja diskurssien välityksellä operoivaa valtaa, jonka on nähty jäsentävän erityisesti seksuaalisuutta ja kuolemaa. ${ }^{12}$ Voitaisiin väittää, että tarve kontrolloida etenkin itsemurhan kaltaista omaehtoista, yksilöä yli yhteisön korostavaa kuolemaa on jokseenkin universaali, ja että läntisissä diskursseissa toistuva ja näitä diskursseja jäsentävä itsemurhatartunta on yksi tällaisen vallan metodeista.
Itsemurhan kohdalla ilmeistä on myös biovallan päällekkäisyys tabujärjestelmään. Kiinnostava aspekti itsemurhatartunnan selitysmalleissa on tällöin niiden hyödyntämässä affektiivisessa tartuntametaforassa, joka Gijin Chengin ja kollegoiden mukaan kätkee puutteellista ymmärrystä tämän tartunnan syy-seurausketjuista. ${ }^{13}$ Mary Douglas asemoi tabun tartunnanpelon voimalla toimivaksi rakenteeksi, joka osallistuu sosiokulttuurisen järjestyksen ja siihen sidotun moraalijärjestelmän ylläpitämiseen. ${ }^{14}$ Tartunnan logiikkansa tähden tabu on tullut toiseutetuksi primitiivisenä järjestelmänä niissä kolonialistisissa differentiaatioissa, joissa esimodernien siirtomaiden kulttuuria ja käytänteitä alennettiin irrationaalisina suhteessa rationaaliseksi miellettyyn länteen. ${ }^{15}$ Tällöin tabu määriteltiin taikauskoksi muun muassa antropologi James Frazerin toimesta, joka näki taikauskon edellyttävän väärinymmärrystä kausaliteetista ja esitti tartunnanpelon varaan pingotetun tabun täyttävän tämän määritelmän negatiivisena sympaattisena magiana. ${ }^{16}$

Samanlainen puute kausaliteetissa toteutuu nähdäkseni myös kyseenalaistamatta käyttöön omaksutussa Werther-efektissä, 
joka edustaa itsemurhatartunnan tieteellisiä selitysmalleja ja esittää itsemurhan tarttuvan median välittämien mallien ja niille altistumisen myötä. Toisin sanoen, kuten artikkelissani esitän, raja tieteen ja taikauskon, rationaalisen ja irrationaalisen välillä näyttäytyy häilyvänä tarkasteltaessa sitä, miten itsemurhan kaltaista vaaralliseksi luokiteltua kuolemaa kotoistetaan mediakulttuurissa. ${ }^{17}$

Valitsemieni tapausesimerkkien välillä vallitsevan laadullisen eron tähden luentani niistä on epäsymmetrinen. Aloitan artikkelini tarkastelemalla Mothin avainkohtauksien avulla sen tapaa kuvata tarttuvaksi miellettyä itsemurhaa ennen tieteellisinä hyväksyttyjä selitysmalleja. Tämän jälkeen erittelen 13 Reasons -sarjan vastaanottoa. Keskityn sarjan sisältöön kursorisesti, niiltä osin kuin se on sarjaa ympäröineen keskustelun osalta oleellista, kommentoidakseni sarjan vastaanottoon vaikuttaneen Werther-efektin suhdetta vallitsevaan itsemurhakuvastoon.

\section{Itsemurhatartunta vampyyrimetaforassa}

Itsemurha on visuaalisessa kulttuurissa hyödynnettävänä indeksinä yleinen, vaikka aiheen temaattinen käsittely on suhteessa harvinaista. ${ }^{18}$ Toisin kuin 13 Reasons, joka edustaa harvinaisempaa temaattista linjaa, valtaosa itsemurhaa sivuavista tai tarkastelevista esityksistä julkaistaan ja vastaanotetaan vailla kohua. Aiheen temaattisen käsittelyn saralta tällaista vailla polemiikkia populaarikulttuuriin hyväksyttyä itsemurhakuvausta edustaa vuonna 2011 julkaistu The Moth Diaries. Elokuva on kanadalaisen Mary Harronin adaptaatio Rachel Kleinin samannimisestä romaanista (2002), jossa itsetuhonsa kanssa kamppailee 16-vuotias päähahmo Rebecca (Sarah Bolger).

Elokuvassa toistuvat monet niistä elementeistä, joiden olen tulkinnut audiovisuaalisessa viihteessä mahdollistavan arkaluontoisen teeman käsittelyn: aihetta tarkastellaan muun muassa rinnakkaiskerronnan, nostalgian ja romantiikan välityksellä, mikä sallii itsemurhan näyttäytyä tietynlaisen rauhoittavan etäisyyden takaa. ${ }^{19}$ Elokuvassa itsemurhahalua myös tarkastellaan nuoren naishahmon välityksellä ja itsemurhan uhka asemoidaan koulukontekstiin, mikä on yleistä etenkin 2000-luvun puolella ilmestyneille esityksille. $^{20}$ Tämän lisäksi populaarikulttuurin kierrättämissä esityksissä toistuvat sukupuolitetut "hulluuden" kuvaukset. Mothin voi kuitenkin nähdä tulkitsevan itsemurhaa kan- sanperinteeseen nojaten: vampyyrifiktion pikemmin kuin diagnoosien välityksellä.

Elokuvan kerronnassa päähahmo palaa kesälomalta toisen vuoden opintoihinsa sisäoppilaitoksessa ja huomaa tulevansa arvoituksellisen uuden oppilaan Ernessan (Lily Cole) syrjäyttämäksi suhteessaan parhaaseen ystävään Lucyyn (Sarah Gadon). Lukukauden edetessä Lucylle kehittyy anoreksia, minkä lisäksi Rebeccan ystäväpiiri kapenee muun muassa selittämättömien kuolemien johdosta. Rebecca syyttää sekä kuolemista että ystävänsä sairaudesta Ernessaa, jota epäilee vampyyriksi kirjallisuuden kurssinsa vaikuttamana. Ernessan taustatarina, joka selviää tytölle vähä vähältä, vahvistaa epäilyt ja kytkee hahmot toisiinsa: Rebecca suree runoilijaisänsä itsemurhaa, ja Ernessa ei koskaan toipunut muusikkoisänsä omaehtoisesta kuolemasta. Tytön toipuminen peilautuukin Ernessan tarinasta: Ernessa surmaa itsensä surussaan, kun taas Rebecca lopulta kieltäytyy jakamasta tämän kohtalon.

Elokuvassa kuvataan yhteensä kuutta itsetuhoa. Kerronnallisessa keskiössä on protagonistipari Rebeccan ja Ernessan itsetuhoisuus, joista kumpikin selittyy itsemurhatartunnalla. Itsemurhan on tunnistettu 
"tarttuvan" myös ikäluokan sisällä ja vanhemmilta lapsille, ${ }^{21}$ ja protagonistiparin alttiuden taustalla vaikuttavat isien itsemurhat. Näistä toinen jopa tuotetaan graafisesti näkyviin elokuvan visuaalisessa kerronnassa. Mainittujen neljän tapauksen lisäksi itsetuho nostaa päätään Rebeccan ystävän putoamiskuolemassa ja Lucyn anoreksiassa. Vampyyri-Ernessan välityksellä sekä Rebeccan tila että Lucyn passiivisen itsemurhan ${ }^{22}$ kriteerit täyttävä anoreksia kytkeytyvät kulttuurihistoriaan, jossa molempia on selitetty demonien viettelyllä. ${ }^{23}$

Erityisesti itsemurhatartunnan tarkasteluun vampyyri on perusteltu metafora historiallisten juurtensa tähden: eurooppalaisessa folkloressa tämä monien eri termien alla kuolleista heräävä hahmo on usein syypukki selittämättömille kuolemille. ${ }^{24}$ Hahmoa määrittelevänä ominaisuutena toimii sen "epäluonnollinen suhde kuolemaan,"25 mikä ilmentyy paitsi hahmon kuolemanjälkeisessä levottomuudessa myös sen olotilaa selittävässä luonnottomassa kuolemassa. "Vampyyriksi" määriteltävien levottomien kuolleiden syntyä on usein selitetty joko ennenaikaisella kuolemalla tai epäonnistuneilla hautajaisriiteillä, ${ }^{26}$ jotka yhdistyvät käytän- teissä haudata itsemurhakuolleet kirkon pyhittämien hautapaikkojen ulkopuolelle. Siten levottomia itsemurhavainajia ja kuolemaa levittäviä "vampyyreita" on tulkittu osana samaa ilmiötä.

Elokuvassa vampyyrin hahmo indikoi kuoleman houkutusta kahdesta näkökulmasta. Sen lisäksi, että vampyyri edustaa epäluonnolliseksi määräytyvää kuolemanhalua, fiktion seksualisoima hahmo ${ }^{27}$ näyttäytyy usein seksuaalisesti transgressiivisena. ${ }^{28}$ Myös Ernessan transgressiivisuus on eskplisiittisesti seksuaalista. Suhteessaan Lucyyn tämä määräytyy lesbiseksi vampyyriksi, joka on yksi vampyyrikuvastomme kierrättämistä vakiohahmoista. ${ }^{29}$ Tästä asemasta vampyyri horjuttaa päähahmon merkittävintä inmissuhdetta ja sidettä elämään. Seksuaalinen houkutus sulautuu itsetuhoon vampyyrin aiheuttaessa Lucyn kuoleman ja houkutellessa Rebeccaa itsemurhalla: ensimmäisen syömishäiriön vihjataan olevan Ernessan vaikutusta ja jälkimmäisen öisin hyväilemän partaterän vampyyrin tälle antama.

Eksplisiittisemmin vampyyrin voi elokuvassa nähdä ilmentävän vanhempien lapsilleen "tartuttamaa" kuolemanhalua. Elokuvan kohtauksissa itsemurhatartuntaa käsitellään tietynlaisena verenperintönä, ja niissä vanhemman aiheuttamasta itsemurhahalusta toipuminen kytkeytyy muistamiseen sekä Elizabeth Kübler-Rossin teorisoimiin suruprosessin vaiheisiin, ${ }^{30}$ mikä käy ilmi sekä kohtausten dialogista että dramatisoinnista. Vampyyri vihjaa itsemurhaan esimerkiksi puhuessaan molempien perimistä taiteellisista lahjoista, minkä tyttö pyrkii kieltämään samalla tavalla kuin elokuvan muissa kohtauksissa kieltää muistavansa isänsä itsemurhan.

Kahden avainkohtauksen toisteisessa sisällössä tyttö istuu koulun kappelimaisessa kirjastossa lukemassa ja kirjoittamassa päiväkirjaansa, kun vampyyri keskeyttää tämän ja houkuttelee tätä itsemurhalla, ensin verbaalisesti, sitten esimerkillään. Ensimmäisessä kohtauksista Ernessa kuvailee kuolemaa ihannoivasti:

Älä sääli isääsi. Eräät aikamme suurimmista taiteilijoista tulivat hulluiksi ja tappoivat itsensä. Jotkut ihmiset saavat suurta iloa kuoleman ajatuksesta. Pelkästään sen ajattelu voi tuntua lohdulliselta, samalla tavalla kuin peiton vetäminen päälleen silloin kun makaa sängyssään. 
Kuoleman hetki on ekstaattinen, se on mitä riemukkain tunne. Silloin synnytään uuteen olemassaoloon.

Vampyyrin puhe keskeyttää tytön itsemurhaan kytkeytyvän pohdinnan: "Henkilö saattaa muuttua vampyyriksi, mikäli kuolee tulematta nähdyksi. Isäni halusi kuolla tulematta nähdyksi, aivan kuten eläin, joka haluaa ryömiä nurkkaan kuolemaan yksin." Molempien avainkohtausten lopussa Rebecca myös löytää pöydältä partaterän, jonka voimme olettaa vampyyrin tälle jättämäksi. Yöllä Rebecca tarkastelee terää sängyssään: "Onko isäni sairaus myös omassa veressäni?," hän pohtii ja teeskentelee viiltävänsä terällä virheetöntä rannettaan: "Kuinkahan paljon se sattui, kun hän teki sen? Veikö se kivun todella pois?"

Toisessa kahdesta avainkohtauksesta itsemurhatartunta ilmentyy sen visuaalisessa kerronnassa. Kohtaus seuraa takaumaa, jossa Rebecca viimein muistaa hautaamansa muistot: muistossaan tyttö pakottaa lukitun kylpyhuoneen oven auki ja löytää isänsä ruumiin lysähtäneenä ammetta vasten - isä on viiltänyt ranteensa, verta on kaikkialla. Avainkohtauksen aloit- tava Ernessan puhe tuntuukin asemoivan tämän graafisesti kuvatun kuoleman myös Rebeccaa itseään uhkaavaksi kohtaloksi. Dialogin päättää Grimmin sadusta "Kataja" lainattu laulu, joka tuntuu niin ikään kuvailevan jatkumoa, jossa vanhemman itsemurha uhkaa myös lasta. Se viittaa tarinaan, jossa paha äitipuoli tappaa ja tietämätön isä hyvällä ruokahalulla syö lapsensa. ${ }^{31}$

Kuva 2: Rebecca (Sarah Gadon) pohtii isänsä itsemurhaa.

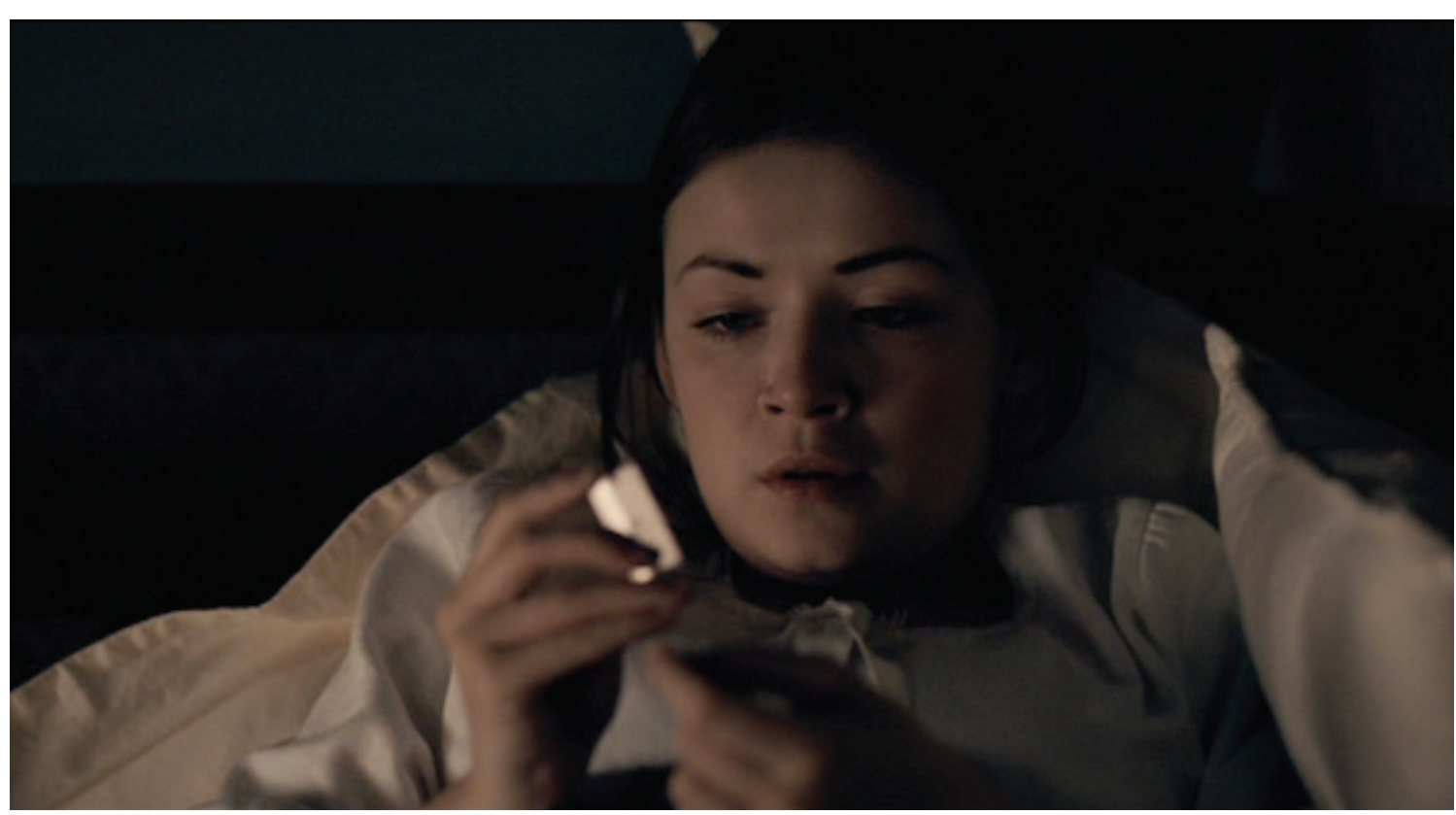
muistan hänestä, kävelyretkemme, ne sadut,
- "[I]säsihän aiheutti sinulle kaiken tämän vaivan."

- "Olet väärässä. Kaikki ne hyvät asiat, jotka joita hän luki minulle, kaikki se oli totta.”

"Hän luki sinulle myös toisenlaisia satuja, jotka olet unohtanut. Äitini mun tappoi, isäni mun söi, Marianna siskoseni kaappi kokoon luuni kaikki, silkki-vaatteesen net kiersi, heselmä-puulle käärön viersi.--”

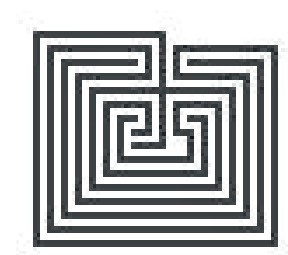


Laulua seuraavassa väkivallanteossaan Ernessa edustaakin Rebeccan pelkojen ja haaveiden lisäksi tämän isää, jonka kuolemaa hahmo toisintaa: hän kohottaa hihaansa ja paljastaa viiltohaavat ranteessaan, sitten viiltää itseään kehottaen: "sinun on aika vapauttaa itsesi." Ernessa levittää kätensä sivulle kuin ristiinnaulittu Kristus, kasvonsa ekstaattiseen ilmeeseen sulaen, kun pöytänsä ääressä Rebecca yrittää suojella itseään haavoista satavalta vereltä. Kun Rebecca tointuu, hän istuu tahrattomassa kirjastossa yksin ja löytää taas partaterän edestään.

Elokuvan lopussa tytön voidaan nähdä "vapauttavan" itsensä itseään uhanneelta itsetuholta: Rebecca tarkastelee terää sängyssään, kunnes sysää sen inhoten pois. Löydettyään Ernessan ruumisarkun koulun kellarista tyttö sytyttää sen tuleen. Elokuva päättyy poliisiasemalle kuljetettavan Rebeccan hankkiutuessa terästä eroon. Tässä mielessä Mothin voi mieltää turvalliseksi tavaksi käsitellä tarttuvaksi määriteltyä itsemurhaa: vampyyrimetaforan avustamana se kuvaa itsemurhahalua, joka tulee päihitetyksi.

\section{Itsemurhatartunta mediakohussa}

Vaikka Netflix-draama 13 Reasons Why tarjoaa monilta osin samanlaisen esityksen itsemurhasta kuin Moth, se on tästä poiketen määritelty itsemurhatartunnan aiheuttajaksi. Sarjassa tarkastellaan syitä 17-vuotiaan tytön, Hannah Bakerin (Katherine Langford), kuoleman taustalla, ja sen ensimmäinen kausi perustuu Jay Asherin samannimiseen kirjaan (2007). Kohun taustalla vaikuttaa sosiologi David Phillipsin nimeämä "Werther-efekti," ${ }^{32}$ median välittämäksi esitetty itsemurhatartunta, joka on tehnyt tulenarkoja sellaisista esityksistä, joiden voidaan tulkita glorifioivan ja romantisoivan ${ }^{33}$ itsemurhaa. Tartunta juontuu Goethen klassikkoteoksesta Nuoren Wertherin kärsimykset (1774), jonka on tulkittu aiheuttaneen Euroopan yli pyyhkineen itsemurha-aallon julkaisuajankohtanaan. ${ }^{34}$

Pääasiassa Anglo-Amerikkalaista maailmaa ravistellut kohu syntyi, kun sarjan ensimmäinen kausi julkaistiin maaliskuussa 2017. Sarjan argumentoitiin ylentävän itsemurhaa ja siten toimivan laukaisevana tekijänä tosielämän itsemurhille, jonka johdosta sarjalle muun muassa vaadittiin korkeampia ikärajoja ja sitä koskenutta keskustelua pyrittiin sensuroimaan erityisesti mielenterveysalan toimijoiden, koulujen ja vanhempien toimesta. Mielipidekirjoituksissa ja viihdejulkaisuissa kritiikin kohteeksi asettuivat etenkin sarjan graafiset kohtaukset ja taipumus kuvata itsemurhahalua vailla masennusdiagnoosin selitysvoimaa ja viittausta ammattiavun sallimiin toipumismahdollisuuksiin. Keskustelu oli kiivaimmillaan huhti-toukokuussa 2017, mutta se on jatkunut myös yli toisen kauden julkaisun toukokuussa 2018, jolloin luvattua kolmatta kautta vaadittiin peruttavaksi.

Sarjan visuaalisen kerronnan osalta kohu oli ennakoitavissa: siinä yhdistyvät kaksi tabua, seksuaalinen väkivalta ja itsemurha, joita kuvataan raa'asti ja kaunistelematta. Graafisuus ei ole harvinaista viihteen itsemurhakuvauksille ylipäänsä, mutta se on poikkeuksellinen sekä genrensä sisällä että narratiivinsa osalta, jossa omaehtoinen kuolema päättää toiseksi päähahmoksi mielletyn hahmon tarinan sarjan huipennuksessa. ${ }^{35}$ Nämä ongelmallisiksi määritellyt tekijät myös korostuvat, kun huomioidaan sarjan huomioarvo sosiaalisessa mediassa ja sen nuorista aikuisista koostuva kohdeyleisö, joka on katalysaattorina tuttu muistakin moraalipaniikeista. ${ }^{36}$ Tällöin sarjan 
tuottanut ja sitä markkinoinut ja puolustanut Selena Gomez näyttäytyy tietynlaisena "ärsykkeenä". Sekä irrationaalisuuden värittämä itsemurha että pelätty tartunta näyttäytyvät juuri nuoruuteen sijoittuvana ongelmana, ${ }^{37}$ ja tässä tapauksessa Disney-tähti Gomez houkuttelee nuoret suoraan ruutujen äärelle.

Sarjan ensimmäisessä jaksossa sen 17-vuotias päähenkilö Clay Jensen (Dylan Minnette) löytää kotiportailtaan pahvilaatikon, jonka sisältämillä C-kaseteilla itsensä surmanneen Hannahin ääni johdattaa poikaa ymmärtämään selittämättömäksi jäänyttä kuolemaansa. Tytöstä otettu pikkupöksyotos ja kuvaa kehystävä vale aiheuttavat tytölle huonon maineen, joka kimpoilee huhuista ja pilkanteosta säröihin tämän ystävyyssuhteissa ja kulminoituu lopulta tytön kokemaan raiskaukseen, josta - kuten Hannah huomaa - patriarkaalinen kulttuuri tapaa syyllistää väkivallan uhria väkivallantekijää enemmän.

Hannah on Clayn toivottoman kouluihastuksen kohde, ja sarjassa Hannahin fataali tarina lomittuu Clayn toipumisprosessiin. Hahmot määrittyvät affiineiksi sekä rinnakkaiskerronnassa että leikkauksissa, joissa hahmojen surut ja vauriot (fyysisetkin) seuraavat toisiaan.
Lopulta hahmot eriävät toisistaan tekemissään valinnoissa: viimeisessä jaksossa Hannah kääntää selkänsä sekä rakkaudelle että elämälle, kun Clay taas ojentaa molemmille kätensä. Samalla tavalla kuin Mothissa, päähahmolle affiiniksi merkityn hahmon fataali taustatarina siis pakottaa päähenkilön kohtaamaan itsemurhakuoleman aiheuttamat padotut tunteet ja mahdollistaa tämän toipumisen.

Sarjaa ympäröinyt kohu on ollut kritiikissään varsin monivivahteinen, ja monet näistä argumenteista on osoitettavissa aiheettomiksi sarjan sisältöjä tarkastelemalla. Yhdeksi sarjan kiistanalaisemmista elementeistä on tuomittu Hannahin postuumi kertojanääni, jonka on tulkittu romantisoivan itsemurhaa koston välineenä ja häivyttävän kuoleman lopullisuutta. ${ }^{38}$ Sarjan viraaliin kieltoon yltäneessä alkulauseessa Hannah lausuu:

Hei, Hannah täällä. Hannah Baker [...] livenä ja stereona. Ei toista keikkaa myöhemmin, ei encorea - ja tällä kertaa: ei missään nimessä toivebiisejä. Hae purtavaa, rentoudu, sillä aion kertoa sinulle elämäntarinani. Tarkemmin sanottuna: miksi elämäni päättyi. Ja mikäli kuuntelet tätä kasettia, olet yksi syy siihen.
Hannahin ääni tuntuu puhuttelevan niin katsojaa kuin surunsa ja syyllisyytensä kanssa kamppailevaa Clayta henkilökohtaisesti. Jokainen kasetti, ja jokainen sarjan kolmestatoista jaksosta, yhtä kasettia ja jaksoa lukuun ottamatta, keskittyy eri henkilöihin. Clay on kymmenes puhutelluista kahdestatoista inmisestä, jotka koostuvat ihastuksista, ystävistä, vihamiehistä ja koulun opinto-ohjaaja Mr. Porterista (Derek Luke). Sarjan edetessä Clay kohtaa kaseteilla nimettyjä hahmoja, ja näiden osuuksia tarinassa avataan syvemmin kuin sarjan alkuteoksessa. Tämän myötä Clay alkaa paremmin ymmärtää hahmojen toimia: näiden syyllisyys ei näyttäydy yhtä mustavalkoisena kuin Hannah esittää, minkä voisi nähdä asettuvan vastakkain sarjan kohtaaman kritiikin kanssa.

Vaikka sarjan on pelätty nimenomaan ylentävän itsemurhaa, siinä viipyillään useiden päähahmon omaehtoista kuolemaa kyseenalaistavien teemojen äärellä. Oleellisessa roolissa ovat erityisesti eloonjääneiden suruun keskittyvät juonikaaret, jotka osoittavat tytön hiljaisuudessa kasvaneen ratkaisun piittaamattomuuden. Hannah kummittelee etenkin vanhempiensa (Kate Walsh ja Brian d'Arcy James) surussa, jota 
tarkastellaan sarjassa raadollisen likeltä. Takaumissa ja haavekuvissa kuvattu romanssi Clayn ja Hannahin välillä taas de-romantisoi tytön kuolemaa. Viimeiseksi sarjan tulokulma seksuaaliseen väkivaltaan horjuttaa tytön ratkaisua vaikka ymmärtää niitä yhteiskunnallisista rakenteista johtuvia kynnyksiä, jotka hankaloittavat seksuaalisen väkivallan uhreja hakemasta itselleen oikeutta toisin.

Kuva 3: Netflixin tuottaman 13 Reasons Why -sarjan ensimmäisellä kaudella (2017) päähahmo Clay (Dylan Minnette) toipuu kouluihastuksensa itsemurhasta. .

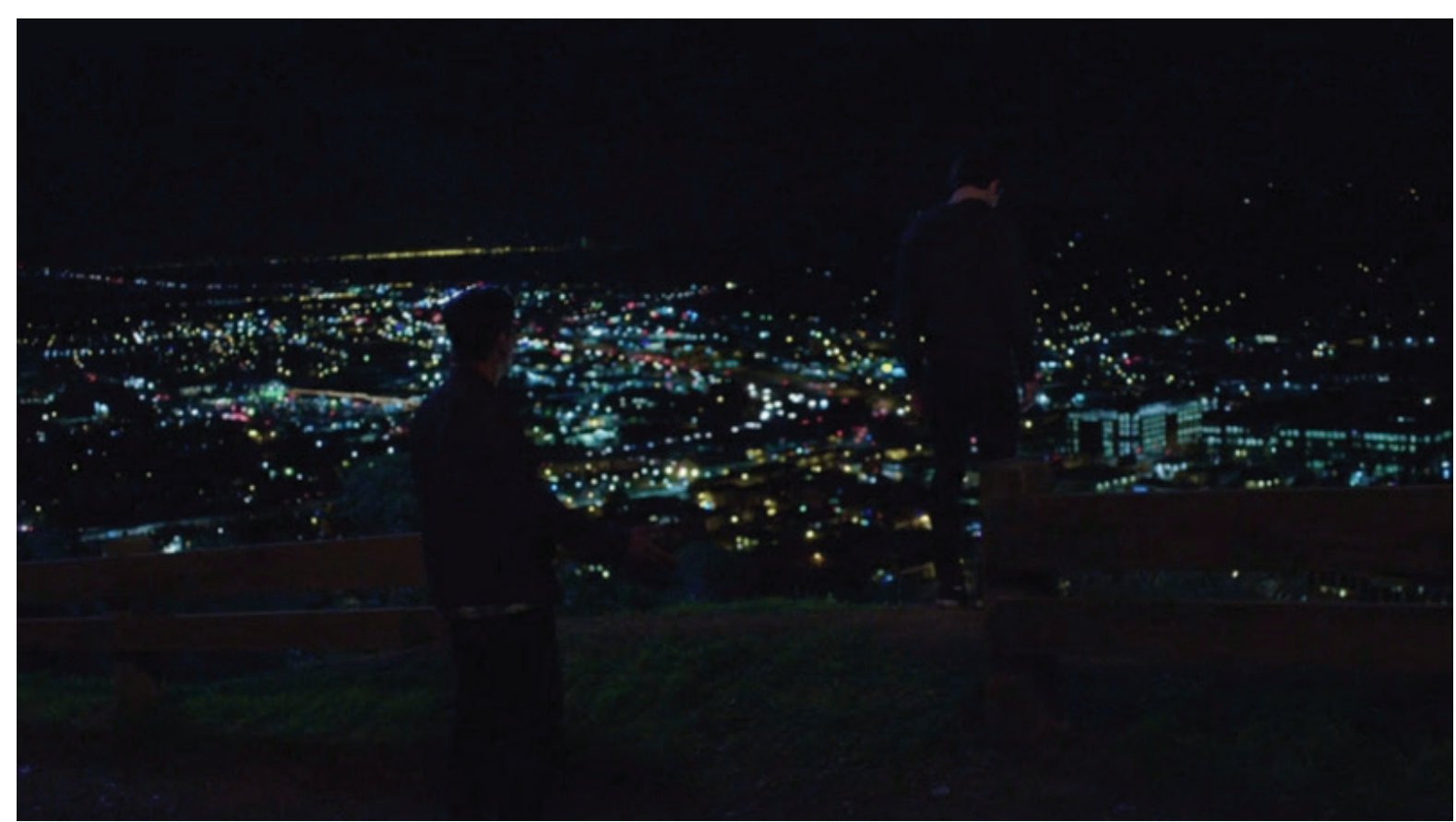

Toisin sanoen, narratiivinsa osalta sarjan ei yksiselitteisesti voida väittää ylentävän itsemurhaa: paitsi että siinä on havaittavissa enemmän elämänmyönteistä kuin itsemurhapositiivista tematiikkaa, se ei suoranaisesti "hyväksy" Hannahin valintaa.

Yksioikoiseen luentaan perustuvan kohun taustalla paistaa itsemurhan asema länsimaisessa moraalijärjestelmässä pa-

haksi määriteltynä kuolemana, joka edellyttää ruumiiseen suuntautuneen biovallan interventioita. ${ }^{39}$ Myös sen kohtelu tabuna voitaisiin mieltää osaksi samaa ilmiötä. Itsemurha on paitsi tabua määrittelevän hiljaisuuden ja eufemististen puheentapojen ympäröimä sensitiivinen aihe, se on myös luonnonvastaiseksi määritelty kuolema, josta erityisen vaarallisen tekee siihen liitetty tartunnan pelko. On huomattava, että itsemurha määrittyy myös tarttuvaksi niissä diskursiivisissa prosesseissa, joissa sitä käsitellään ja kotoistetaan poissulkevassa suhteessa luonnolliseen, hyvään kuolemaan.

Itsemurhan kotoistaminen tarttuvana kuolemana yltää sen asemaan mediassa ja populaarikulttuurissa. Vaikka sensitiivinen aihe on kulttuurissamme varsin näkyvässä roolissa, sen tabuus näyttäytyy olemassa olevan kuvaston yksipuolisuudessa ja käsityksissämme siitä, miten omaehtoista kuolemaa voi kuvata. Olen toisaalla ehdottanut, että itsemurhaa kehystävissä narratiiveissa on nähtävissä pyrkimys tarttuvaksi ja pelottavaksi mielletyn "pahan kuoleman" kesyttämiseen. ${ }^{40}$ Audio-visuaaliselle viihteelle ominaisten, naisiseksi sukupuolitettujen ${ }^{41}$ ja hulluuden kehystämien narratiivien voi näh- 
dä osallistuvan omaehtoisen kuoleman alentamiseen naiseuteen ja hulluuteen liitettyjen heikkouden ja irrationaalisuuden attribuuttien välityksellä, jotka korostavat itsemurhan alhaista luonnetta. Voitaisiinkin esittää, että mediaesitysten kavalkadi on olemassa olevasta etiketistä ja omaehtoiseen kuolemaan liittyvistä käsityksistä johtuen valtaosin stigmatisoiva, niin sanotusti biovallan alla kesytetty.

Tältä osin 13 Reasons -sarjan kohtaamassa kohussa oireellista on etenkin ongelmalliseksi tulkittu tapa kuvata hahmon itsemurhaa psykiatristen diagnoosien ja terapeuttisten apukeinojen ohi. ${ }^{42}$ Erityisesti kun huomioidaan, että Hannahin masennus on vastaanotossa vaadittujen verbaalisten indikaattorienkin puuttuessa ilmeinen: mielialahäiriön kulttuurisesti tunnistettavat merkit ovat läsnä sekä Hannahin alakulossa että Claylle hankitussa lääkityksessä, minkä lisäksi diagnostiikka ja hätälinjat esiintyvät sekä jaksoja edeltävissä varoituksissa että sarjaa täydentävässä dokumentissa.

Kritiikki tuntuisi oirehtivan tabun määrittämää moraliteettia etenkin siinä, että se kytkee pelon itsemurhan glorifioinnista sarjan tapaan kuvata tätä kuolemaa rationaalisena päätöksenä. Kuten tiukempia ikärajoituksia suosittanut auktoriteetti perustelee: "Itsemurhaa ei pitäisi esittää kenellekään jonakin, mikä seuraa selväjärkisestä ajattelusta." ${ }^{43}$ Psykologit ovat kuitenkin esittäneet, että vaikka itsemurhan taustalla usein piilee jonkinlainen "psyykkinen kiputila," tekona se edellyttää tietoista päätöstä, ${ }^{44}$ jota tunteen lisäksi ruokkivat usein myös monenlaiset sosioekonomiset, järkeenkäyviksi määriteltävissä olevat tekijät. ${ }^{45}$ Tältä osin sarjan kuvaus yksinäisyyden ja monen takaiskun vaikutuksesta kumuloituvasta ratkaisusta on realistisempi kuin valtaosa viihteen epämääräisen "hulluuden" motivoimista itsemurhakuvauksista.

Juuri tämän itsemurhan ylentämiseen kohdistuvan huolen taustalla vaikuttavassa Werther-efektissä huomionarvoista taas on se, että efektiä on ollut yhtä hankala kiistää kuin todentaa: kuten mallin kohtaama kritiikki huomauttaa, alkujaan uutismedian puitteissa tarkasteltua tartuntaa fiktiivisiin esityksiin sovitettaessa ei ole riittävästi huomioitu esimerkiksi fiktiivisyyden, genren tai muiden laadullisten seikkojen vaikutusta. ${ }^{46}$ Tutkimukset ovat myös kohdanneet epistemologista ja metodologista kritiikkiä, ${ }^{47}$ minkä lisäksi löydettyjä korrelaatioita ei ole kyetty todentamaan. ${ }^{48}$ Mediapaniikkien ja Werther-efektiä tarkastelleiden tutkimusten taustalla näyttäisi myös vaikuttavan simplistinen käsitys sekä itsemurhasta että televisiota katsovista nuorista. ${ }^{49}$ Toteutuessaan itsemurha edellyttää monien altistavien tekijöiden yhteisvaikutusta jopa silloin, kun kyseessä ovat vaikutteille alttiiksi mielletyt yleisöt. ${ }^{50}$ Kuten muidenkin mediaväkivallan esitysten, ${ }^{51}$ myös itsemurhan representaatioiden vaikutuksia tarkasteltaessa olisi syytä kyseenalaistaa huolen taustalla häämöttävä injektioneulamallinen käsitys mallioppimisesta. ${ }^{52}$ Toisin sanoen: vaikka omaehtoisen kuoleman voisi nähdä tarttuvan ideana, se ei tekona selity yksinomaan itsemurhan mahdollisia järkisyitä tarkastelevilla representaatioilla, toisin kuin Werther-efektiin tukeutuvat diskurssit esittävät. ${ }^{53}$

13 Reasons -sarjan kohtaama kritiikki asettuu mittasuhteisiinsa, kun sarjaa tarkastellaan kokonaisuutena ja suhteutetaan vallitsevaan kuvastoon: on huomionarvoista, että ruutumme ovat medikalisoituneet siinä määrin, että niiden itsemurhanarratiivien voisi väittää olevan lääketieteellisten diagnoosien ja terapia-avusteisten parantumiskertomusten kolonisoimia. ${ }^{54}$ Myös näiden narratiivien 
voisi esittää olevan omalla tavallaan ongelmallisia: lääketieteellisiin diagnooseihin on havaittu liittyvän paljon häpeää,, ${ }^{55}$ ja niiden on esitetty jopa olevan yksi samaistumispintaa rakentava tekijä. ${ }^{56}$ Siten myös diagnooseja ja itsemurhan poikkeuslaatua korostavat esitykset saattavat "tartuttaa" häpeän, 57 stigmaan pohjaavan identifikaation tai näiden aiheuttaman eristyneisyyden kautta. Tällöin populaarikulttuurin valtavirrasta puuttuvien, itsemurhahalua ymmärtävien esitysten voisi väittää jopa lievittävän itsemurhan kanssa kamppailuun liittyvää häpeää.

\section{Itsemurhatartunta \\ pelonhallintamekanismina}

Huomionarvoista 13 Reasons Why -sarjassa on etenkin sen ero The Moth Diaries -elokuvaan, joka eroaa edellisestä vastaanotossaan, vaikka on sisällöllisesti huomattavan samankaltainen: molemmat toistavat sellaisia valtavirtaistuneita trooppeja, jotka yleensä mahdollistavat itsemurhan käsittelyn viihteessä. Tällöin vampyyrifiktion kautta itsemurhaa tarkasteleva Moth sekä avaa sarjan aiheuttamaa kohua että sallii Werther-efektin rinnastamisen niihin samansisältöisiin uskomuksiin, jotka ovat sitä edeltäneet.
Ensinnäkin, jos Netflix-sarjassa on koettu ongelmalliseksi sen empaattinen tapa kuvata itsemurhaan päätyvän nuoren naisen motivaatioita, Mothin voisi väittää olevan tietyissä piirteissään ongelmallisempi. Harronin tekemien rakenteellisten ratkaisujen tähden elämä voittaa elokuvassa kuoleman yksiselitteisemmin kuin romantisoinnista syytetyssä sarjassa, mutta sen esitystä itsemurhasta voi pitää edellistä romantisoivampana: siinä omaehtoista kuolemaa ylentävät sekä sek-

Kuva 4: Hannahin (Katherine Langford) masennus tuotetaan näkyviin sarjan visuaalisessa kerronnassa. .

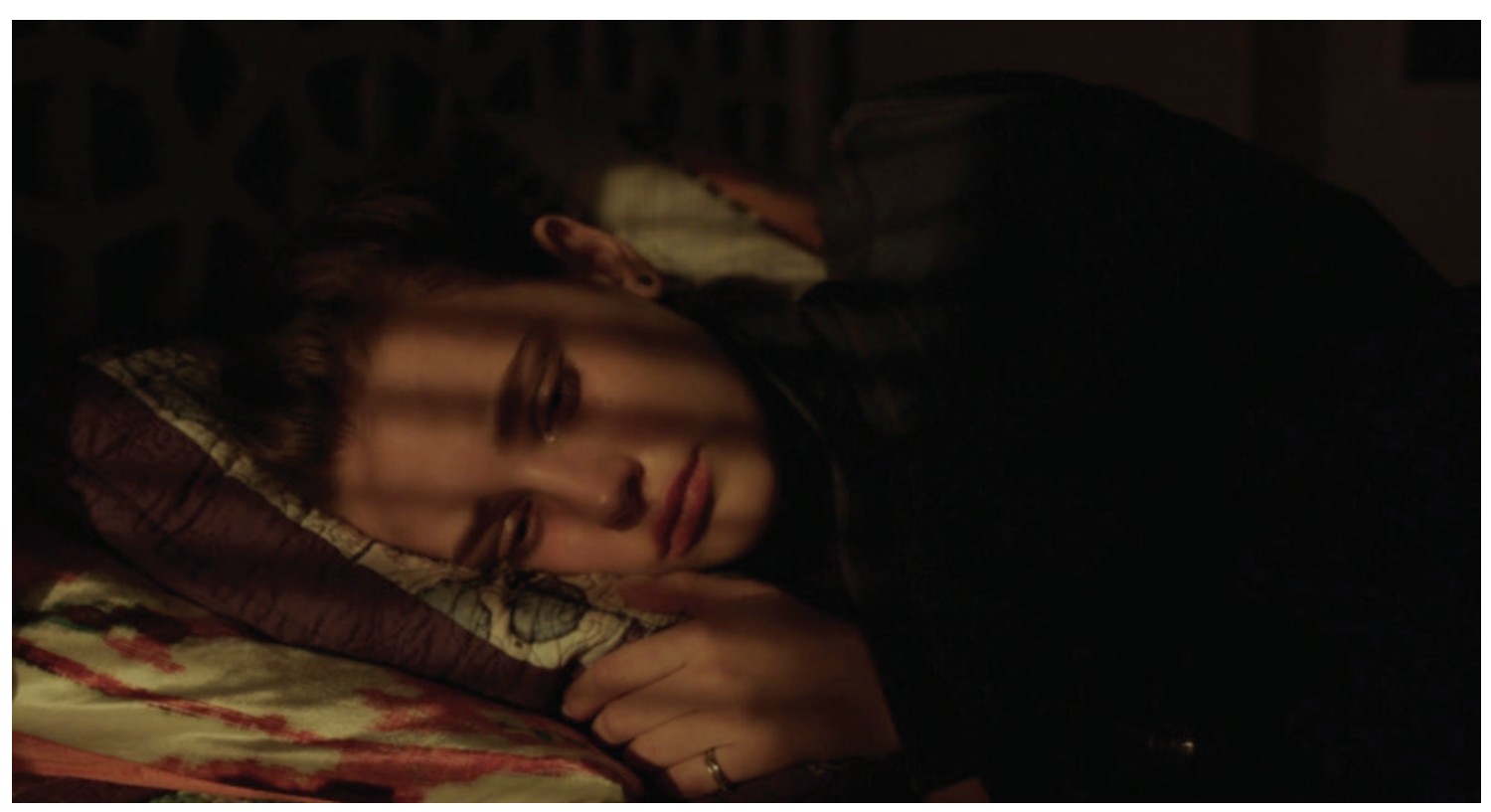

sualisoitu vampyyrin hahmo että avainkohtauksissa hyödynnetyt kristillinen ikonografia ja taiteilijaitsemurhaa ylentävä dialogi. Kuvauksessaan Moth ja 13 Reasons ovat yhtä graafiset. Tuntuukin oireelliselta, että sarjan korotettujen ikärajojen taustalla vallitsee huoli siitä, että irrationaalisuuden kautta määritellylle itsemurhalle löydetään sarjassa järkisyitä. Huoli osoittaa, millaisista arvolatautuneista tausta-asetelmista käsin sosiokulttuurista järjestystä uhkaavan

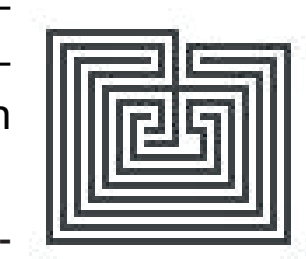


itsemurhan esityksiä tuotetaan ja säädellään.

Mothin irtaantumista Netflix-sarjaa koskeneessa kohussa peräänkuulutetuista diagnooseista avustaa sen paikoittuminen kahden genren väliin: etenkin kauhun itsemurhakuvauksissa kiertävät diagnooseista poikkeavat selitysmallit. ${ }^{58}$ Mothissa hyödynnetty on vielä harvinaisen osuva. Vampyyriuskomukset ovat folkloristien mukaan tarjonneet keinon hallita kuolemaan liittyviä

pelkoja, minkä lisäksi Mary Hallab rinnastaa niiden funktion tieteellisiin selitysmalleihin: "Kansanperinteen vampyyri tarjoaa käytännönläheisen ymmärryksen sellaisiin elämään liittyviin ilmiöihin, kuten sairauteen tai kuolemaan, jotka tuntuvat karttavan järkevää selitystä, ja tarjoaa keinon niiden käsittelyyn". 59

Voitaisiin esittää, että vampyyrin kaltainen metafora koetaan edelleen turvalliseksi tavaksi käsitellä itsemurhan kaltaista, elämän

\section{Kuva 5: Sarjaa kohdannut kritiikki asettuu vastakkain sen elämänmyön-} teisen viestin kanssa.

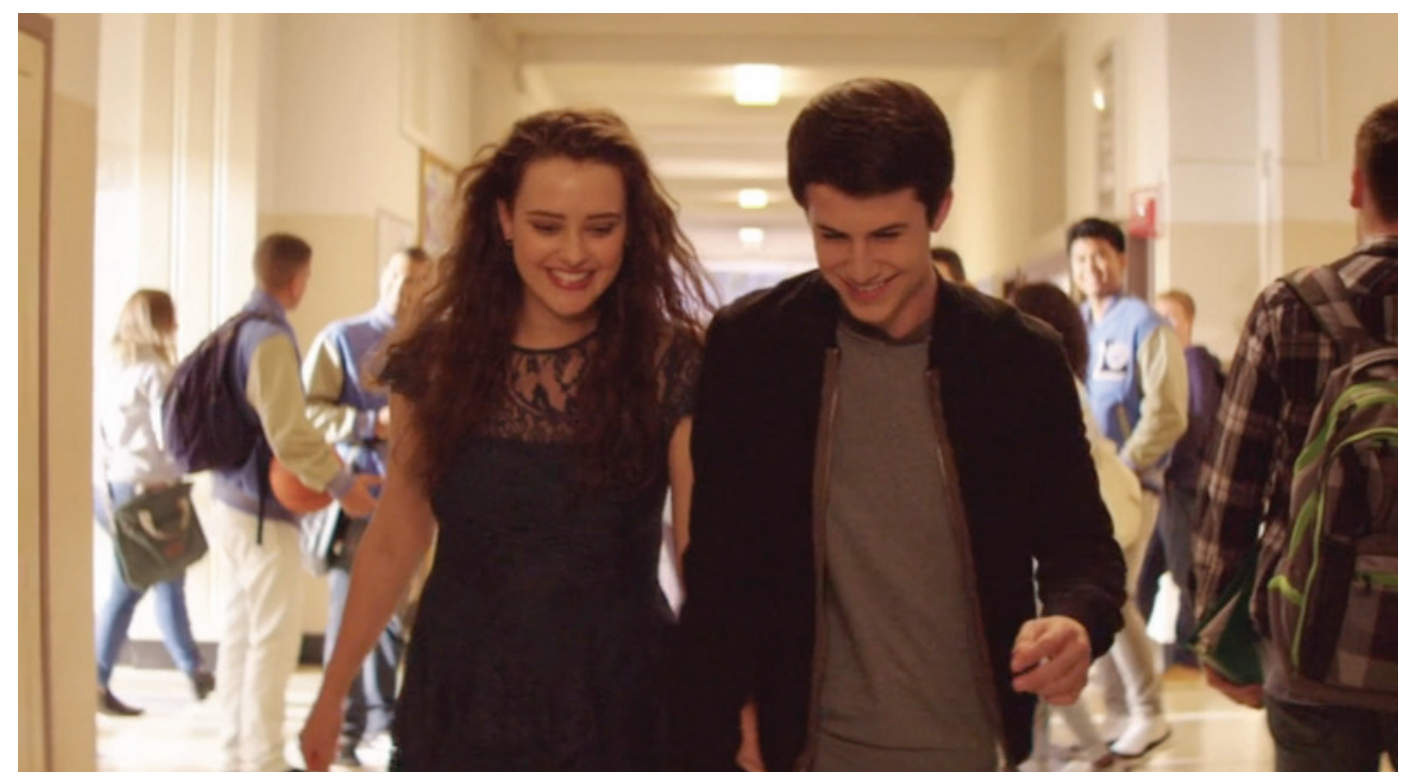

ja kuoleman rajalla "luonnottomasti" häilyvää inmismielen arvoitusta. Hahmo on yksi suosituimmista "välitilaisista" hirviöistämme, ja Tony Thornen mukaan se muuntautuu indikoimaan mitä hyvänsä, mitä yhteiskunta karttaa, mutta salaa kaipaa. ${ }^{60}$ Vampyyrin on nähty osallistuvan etenkin sosiokulttuurista kesyttämistä edellyttävän kuoleman hallintaan. ${ }^{61}$ William Patrick Day ehdottaakin, että elämän ja kuoleman, inmisyyden ja toiseuden rajamailla häilyvä hirviö auttaa ymmärtämään inmisyyttä turvallisen etäisyyden takaa: folkloresta tutut vampyyrit edustavat menneisyyttä. ${ }^{62}$ Siten vampyyrin avulla voidaan käsitellä sellaisia perustavanlaatuisia tarpeita, haluja ja pelkoja ${ }^{63}$ sekä yhteiskunnallisesti relevantteja aiheita, joita ei voida tarkastella eksplisiittisissä muodoissa, kuten itsemurhaa. ${ }^{64}$

Toiseksi Mothin vampyyri jakaa historiallisen kytköksen 13 Reasons -sarjaa kohdanneeseen Werther-efektiin. Kansanperinteen vampyyritapausten on ehdotettu selittyvän tartuntataudeilla, jotka ovat aiheuttaneet paljon kuolemaa yhteisön sisällä. ${ }^{65}$ Day ehdottaa, että vampyyrin hahmo on alun perin selittänyt kuolettavien sairauksien nopeaa leviämistä aikana, jolloin tartunnan meka- 
nismit ovat vielä olleet hämärät. Näin ollen vampyyri on toiminut "metaforana, joka antoi inmisen hahmon viruksille ja bakteereille". ${ }^{66}$ Siten, kuten Outi Hakola kuvaa, sekä alkusijoillaan että nykymuodossaan vampyyri edustaa pelkoa siitä, että kuolema aiheuttaa lisää kuolemaa. ${ }^{67}$ The Moth Diaries -elokuvassa tämä historia oirehtii "transgressiivisessa, subversiivisessa ja jopa vallankumouksellisessa" vampyyri-Ernessan hahmossa, joka uhkaa "muuttaa elävät kaltaisekseen"68 asetuttuaan itsemurhassaan vallitsevaa järjestystä vastaan. 13 Reasons Why -sarjassa sama historia taas ilmenee valtavirrasta poikkeavaan itsemurhaesitykseen liitetyssä tartunnanpelossa ja tämän pelon herättämässä mediapaniikissa.

Kuten Werther-efektin kohtaamasta kritiikistä voidaan kuitenkin päätellä, omaehtoisen kuolemaan reagoidaan toistaiseksi pahimpien mahdollisten uhkakuvien pohjalta ja sellaisten olettamusten varasta, joita ei ole onnistuttu vahvistamaan. Qijin Cheng kollegoineen jopa kritisoi itsemurhatartuntaa käsitteenä, joka on "sallinut tutkijoiden siteerata toisiaan omien argumenttiensa tueksi joutumatta paneutumaan niihin eroihin, jotka heidän tutkimuksiaan erottavat." ${ }^{\text {" }}$ Cheng kollegoineen huomauttaa, että suurimmassa osassa tapauksia tartunnaksi määritelty siirtymä ei toteuta tartunnan kriteereitä vaan pelkästään hyödyntää termiä affektiivisena metaforana, mikä on mahdollistanut laadullisesti varsin erilaisten mekanismien sekoittumisen yhteen ja auttanut selitysmallia juurtumaan. $^{70}$

Tämä tekee aiheen kiinnostavaksi myös tieteen ja taikauskon, irrationaalisen ja rationaalisen väliseen kahtiajakoon liittyen. Kritisoitua itsemurhatartuntaa voisi selitysmallina määritellä taikauskoiseksi, mikäli määrittelemme taikauskon kuten tabua tarkastellut Frazer: pelkoon pohjaavana tulkintana, jonka pohjalla operoi väärinymmärrys kausaliteetista. ${ }^{71}$ Esitys muuttuu erityisen relevantiksi, kun tarkastelun kohteena on kuoleman kaltainen ilmiö, joka mielletään psykologisesti pelottavaksi ja yhteisön kannalta vaaralliseksi, ja joka siksi vaatii sen vaaraa kesyttäviä toimenpiteitä. Itsemurhatartunta heijastuu tällöin samankaltaisista, etäisyyden suojaamista kansanperinteen uskomuksista, joita populaarikulttuurimme nykyään kierrättää fiktiona.

Erityisesti se, että itsemurhatartunnan voi väittää operoivan mediassa tartuntaan liitet- tyjen pelkojen voimalla antaa todistuksen niistä arvolatautuneista eronteoista, jotka yhä auttavat rakentamaan kuvaa lännestä kehityksen pinaakkelina. Tartunnanpelkoon kytketty tabujärjestelmä ei vastaa läntistä ideaalia rationaalisesti toimivasta yhteiskunnasta, minkä tähden se on historiassaan tullut määritellyksi "magiaksi" ja nykyään tulee monesti yksilöidyksi trauman ja uskonnollisen vakaumuksen kaltaisten tekijöiden kautta. Tästä huolimatta tabulle ominaisen tartunnanpelon voisi nähdä vaikuttavan useiden tabuilmiöiden vastaanotossa lännessä aina institutionaaliselta tasolta lähtien. Esimerkiksi kuvaamani itsemurhatartunta vaikuttaa siinä populaarikulttuurisessa kuvastossa, josta 13 Reasons tietyiltä osin poikkeaa, vaikka se muuttuukin eksplisiittisesti näkyväksi vasta tämänkaltaisissa sensuurivaatimuksissa, jotka poikkeavaan esitykseen välittömästi liitetään.

Loppuun on todettava, että vaikka artikkelini suhtautuu kriittisesti Werther-efektiin, tarkoitukseni ei ole kiistää ilmiötä vaan problematisoida ristiriitaisia tuloksia tuottavien hypoteesien valtaa mediakoneistossa, joka vaikuttaa sekä itsemurhaesityksien muotoon että vastaanottoon. Tarkoitukseni 
ei myöskään ole syyttää aiheeseen liittyviä keskusteluja irrationaalisiksi siinä arvolatautuneessa asetelmassa, jossa irrationaalinen usein tulee erotelluksi rationaalisesta. Lähtökohtani on uskomuksessa, että taikauskoisiksi määrittelemämme, vaaralliseen kuolemaan liitetyt uskomukset ja niitä seuranneet selitysmallit ovat osa samaa jatkumoa, jossa kuoleman kaltaista yleismaallisesti pelottavaa ilmiötä on pyritty selittämään. Nykyään vaaralliseksi määriteltyä itsemurhakuolemaa pyrkivät kaitsemaan diagnoosit, Werther-efektin kaltaiset hypoteesit, ja näiden kolonisoimat sekä säätelemät viihteen esitykset, joissa itsemurhatartunnan kohteina toimivat usein nuoret, irrationaalisuuden määrittelemät naiset ja psykopatologian kourissa kamppailevat "hullut". Entisten vampyyriuskomusten lailla näiden voisi nähdä toimivan keinoina hallita tarttuvaksi määriteltyä kuolemaa juuri tietyistä lähtökohdissa kumpuavina pelonhallintamekanismeina.

\section{Viitteet}

1 Haluaisin kiittää vertaisarvioitsijoitani.

2 Artikkelin käännökset ovat omiani, ellei toisin mainita.

3 Patrick Devitt, "13 Reasons Why and Suicide Contagion," Scientific American 8.5.2017, luettu 9.3.2018, https://www.scientificamerican com article/13-reasons-why-and-suicide-contagion1/

4 Itsemurhan historia lännessä ei ole yksioikoinen, joten on tärkeää huomauttaa, että artikkelini fokuksessa ovat egoistisen itsemurhan kuvaukset, jotka on erotettava altruistisista itsemurhista. Jälkimmäisiin liitetään usein yhteisöllisesti hyväksyttyjä utilitaristisia arvoja, toisin kuin egoistisiin itsemurhiin, joita selitetään usein puutteellisella sosiaalisella integraatiolla ja paikannetaan marginaaliin. Émile Durkheim, Suicide: A Study in Sociology (New York: The Free Press, 1966).

5 Edwin Shneidman, "Foreword", teoksessa Survivors of Suicide, toimittanut A.C. Cain (Springfield, Charles C. Thomas, 1973), ix-xi.

6 Jia Tolentino, "13 Reasons Why" Makes a Smarmy Spectacle of Suicide," The New Yorker 10.5.2017. luettu 6.3.2018, URL: http://www.newyorker.com! culture/jia-tolentino/13-reasons-why-makes-asmarmy-spectacle-of-suicide. Suomalaisessa mediassa esim: "Teinitytön itsemurhaa käsittelevä hittisarja kuohuttaa," Nyt 28.4.2017, luettu 3.4.2018, URL: https://www.hs.fi/nyt/art-2000005189586.html 7 JD Knapp, "'13 Reasons Why': Canadian Schools Ban All Talk, Issue Warnings About Netflix Series," Variety 28.4.2018, luettu 9.3.2018, URL: http://variety. com/2017/tv/news/13-reasons-why-netflix-canadianschool-bans-talk-1202403323/

8 Eleanor Ainge Roy, "13 Reasons Why: New Zealand bans under-18s from watching suicide drama without adult," The Guardian 28.4.2018, luettu 9.3.2018, URL: htttps://www.theguardian.com/ world/2017/apr/28/13-reasons-why-new-zealandbans-under-18s-from-watching-suicide-dramawithout-adult
9 David P. Phillips, "The Influence of Suggestion on Suicide: Substantive and Theoretical Implications of the Werther Effect," American Sociological Review vol. 39, no. 3 (1974): 340-54

10 Gijin Cheng et al, "Suicide Contagion: A Systematic Review of Definitions and Research Utility," PLoS ONE vol. 9, no. 9 (2014): 1-9.

11 James B. Hittner, "How Robust is the Werther Effect? A Re-examination of the suggestion-imitation model of suicide," Mortality vol. 10, no. 3 (2005):

193-200; Alan L. Berman, "Fictional depiction of suicide in television films and imitation effects," The American Journal of Psychiatry vol. 145, no. 8 (1988): 982-85.

12 Giorgio Agamben, Homo Sacer: Sovereign Power and Bare Life (Stanford: Stanford UP, 1995); Michel

Foucault, 1976. The History of Sexuality. Volume I: An Introduction (New York: Vintage Books, 1976)

13 Cheng et al, "Suicide Contagion," 7.

14 Mary Douglas, Purity and Danger: An analysis of concept of pollution and taboo (Lontoo ja New York: Routledge, 2002).

15 Franz B. Steiner, "Taboo," teoksessa Franz Baerman Steiner Selected Writings Volume I: Taboo, Truth and Religion, toimittaneet J. Adler ja R. Fardon (New York ja Oxford: Berghahn Books, 1999), 103-219.

16 J.G. Frazer, The Golden Bough. A Study of Magic and Religion (London: Wordsworth Reference, 1993.

17 Sanna Karkulehdon käännöstermi viittaa alkujaan "seksuaalisuuden julkiseen kesyttämiseen". Sanna

Karkulehto, Seksin mediamarkkinat (Helsinki:

Gaudeamus, 2011): 105-122.

18 Michele Aaron, Death and the Moving Image: Ideology, Iconography \& I (Edinburgh: Edinburgh UP, 2014).

19 Heidi Kosonen, "Hollywoodin nekromanssi. Naisen ruumiiseen kiinnittyvä itsemurha elokuvien sukupuolipolitiikkana," teoksessa Sukupuoli ja väkivalta: lukemisen etiikkaa ja politiikkaa toimittaneet S. Karkulehto \& L. Rossi (Helsinki: SKS 
2017): 95-119.

20 ibid, 106.

21 Julie Cerel, John R. Jordan ja Paul R. Duberstein

"The Impact of Suicide on the Family," Crisis vol. 29,

no. 1 (2008): 38-44; Franklin Cook, "The Impact of

Suicide on People Exposed to Fatality," Action

Alliance for Suicide Prevention 6.5.2015, luettu

9.3.2018, URL: https://www.slideshare.net/fjamesc/l research-impactofsuicide-nationalguidelines

22 Durkheim, Suicide, 44

23 Georges Minois, History of Suicide: Voluntary

Death in Western Culture (Baltimore: John Hopkins

UP, 1999); Walter Vandereycken ja Ron van Deth,

From Fasting Saints to Anorexic Girls: The History of

Self-Starvation (Lontoo: The Athlone Press), 14-46.

24 Paul Barber, Vampires, Burial, Death (New Haven

ja Lontoo: Yale UP, 1988).

25 Outi Hakola, Rhetoric of Modern Death in

American Living Dead Films (Intellect: Bristol, 2015),

6.

26 Michael E. Bell, "American Vampires and the Ongoing Ambiguity of Death," Kritikos vol. 10 (2013). 27 Ken Gelder, Reading the Vampire (Lontoo ja New York: Routledge, 1994), 141.

28 Kathleen L. Spencer, "Purity and Danger: Dracula, The Urban Gothic, and Late Victorian Degeneracy Crisis," ELH vol. 59, no. 1 (1992): 197-225.

29 Bonnie Zimmerman, "'Daughters of Darkness': Lesbian Vampires," Jump Cut vol. 24-25 (1981): 23-4.

30 Elizabeth Kübler-Ross, On Death and Dying (London: Tavistock, 1970).

31 "Kataja," Grimmstories.com, luettu 22.3.2018, URL: https://www.grimmstories com/fi/grimm sadut/ kataja. Kiitän Pauline Greenhilliä yhteyden osoittamisesta.

32 Madelyn Gould, Patrick Jamieson ja Danie Romer, "Media Contagion and Suicide among the Young," American Behavioral Scientist vol. 46, no. 9 (2003): 1269-84; Phillips, "Influence of Suggestion on Suicide".
33 Patrick Edwin Jamieson, Changes in U.S. Popular Culture Portrayal of Youth Suicide: 1950-2000 (PhD Dissertation: University of Pennsylvania, 2001); Alexa Curtis, "Does '13 Reasons Why' Glamorize Teen Suicide?," RollingStone 14.4.2017, luettu 6.3.2018, URL: http://www.rollingstone.com/tv/features/ does-13-reasons-why-glamorize-teensuicide-w476303.

34 Frank Furedi, "The Media's First Moral Panic," History Today vol. 65, no. 11 (2015): 46-8.

35 Steven Stack, "Celebrities and Suicide: A

Taxonomy and Analysis, 1948-1983," American Sociological Review no. 52, vol. 3 (1987): 401-12

Benedikt Till et al, "Who Identifies with Suicidal Film Characters? Determinants of Identification with Suicidal Protagonists of Drama Films," Psychiatria Danubina vol. 25, no. 2 (2013): 158-62.

36 Harri Kalha, "What the hell is the figure of the child? Figuring out figurality in, around, and beyond Lee Edelman", Lambda Nordica vol. 16, no. 2-3

(2011): 17-48; Kenneth Thompson, Moral Panics (Lontoo ja New York: Routledge, 1998).

37 Gould, Suicide among the Young.

38 Jaelea Skehan, "Six Reasons Why I'm concerned about a TV series," Linkedln 18.4.2017, luettu 6.3.2018, URL: https://wwww/linkedin com/pulse/6reasons-why-im-concerned-tv-series-jaelea-skehan/ 39 Ian Marsh, Suicide: Foucault, History and Truth (Cambridge: Cambridge UP, 2010).

40 Heidi Kosonen, "The Death of the Others and the Taboo: Suicide Represented," Thanatos vol. 4, no. 1 (2015), 25-56.

41 Populaarikulttuurin sukupuoliasetelma poikkeaa egoistista itsemurhaa koskevista tilastoista. Vrt. Anu Salmela, "Epäpoliittinen itsemurha," AntroBlogi 1.2.2018, luettu 7.3.2018, URL: https://antroblogi. fi/2018/02/epapolittinen-itsemurhal. Ks. myös Silvia Canetto, "She Died for Love, He for Glory: Gender

Myths of Suicidal Behavior," Omega: Journal of Death and Dying vol. 26, no. 1 (1993), 1-17.

42 Sarah-Nicole Bostan, "13 Reasons Why We Need to Talk about Clinical Depression," Psychology Today 21.5.2017, luettu 6.3.2018, URL: https://www.

psychologytoday.com/us/blog/greater-the-sum-itsparts/201705/13-reasons-why; Deborah Serani, "13 Reasons Why: The Good, the Bad and the Ugly," Psychology Today 16.5.2017, luettu 6.3.2018, URL: https://www.psychologytoday com/blog/two-takesdepression/201705/13-reasons-why-the-good-thebad-and-the-ugly; Sansea L. Jacobson, "Thirteen Reasons to Be Concerned About 13 Reasons Why," Pitzburg Post-Gazette 14.5.2017, luettu 6.3.2018, URL: http://wwww.post-gazette com/opinion/OpEd/2017/05/14/Thirteen-reasons-to-be-concernedabout-13-Reasons-Why/stories/201705140106 43 "13 Reasons Why: our reasons for the RP18 classification," Office of Film \& Literature

Classification 27.4.2018, luettu 3.4.2018, URL: https:// www. classificationoffice govt.nz/blog/13-reasonswhyy!!.".

44 Michael J. Kral, "Suicide as Social Logic," Suicide \& Life-Threatening Behavior vol. 24, no. 3 (1994): 245.

45 Edwin Shneidman, "Some Controversies in Suicidology: Toward a Mentalistic Discipline," Suicide and Life-Threatening Behavior vol. 23, no. 4 (1993): 292-98.

46 Steven Stack, Michael Kral \& Teresa Borowski, "Exposure to Suicide Movies and Suicide Attempts: A Research Note," Sociological Focus vol. 47, no. 1 (2014): 61-70.

47 James N. Baron ja Peter C. Reiss, "Same Time, Next Year: Aggregate Analysis of the Mass Media and Violent Behavior," American Sociological Review vol. 50, no. 3 (1985): 347-63.

48 Hittner, "How Robust is the Werther Effect?"; Berman, "Fictional depiction of suicide".

49 Stack et al, "Exposure to Suicide Movies". 50 Kral, "Suicide as Social Logic:" 245-55; David Lester, Making Sense of Suicide: An In-depth Look at Why People Kill Themselves (Philadelphia: The Charles Press, 1997). 
51 Nicola Rafter, Shots in the Mirror: Crime Films and Society (New York: Oxford UP, 2006.)

52 Baron ja Reiss, "Same Time, Next Year".

53 Kral, "Suicide as Social Logic:" 245-55; David

Lester, Making Sense of Suicide: An In-depth Look

at Why People Kill Themselves (Philadelphia: The

Charles Press, 1997).

54 Marsh, Foucault, History and Truth; Steven Stack ja Barbara Bowman, Suicide Movies: Social Patterns

1900-2009 (Cambridge: Hogrefe Publishing, 2012).

55 Barry Lyons ja Luna Dolezal, "Shame, stigma and medicine," Medical Humanities vol. 43, no. 4 (2017):

208-10.

56 Stack, "Celebrities and Suicide": 410.

57 D.H. Buie ja J.T. Maltsberger, "The Psychologica

Vulnerability to Suicide," teoksessa Suicide:

Understanding and Responding, toimittaneet

D. Jacobs ja N. Brown (Madison: International

Universities Press, 1989), 59-71.

58 Huomaa kuitenkin taiteilijaitsemurhan vakaa

asema populaarikulttuurissa. Steven Stack ja

Barbara Bowman, "Suicide Motives in 61 Works of

Popular World Literature and in Comparison to Film,"

teoksessa Suicide and the Creative Arts, toimittaneet

S. Stack ja D. Lester (New York: Nova Science

Publishers, 2009), 113-24.

59 Mary Y. Hallab, Vampire God: The Allure of the

Undead in Western Culture (Albany: State University

of New York Press, 2009), 13.

60 Tony Thorne, Children of the Night: Of Vampires

and Vampirism (Lontoo: Gollancz, 1999), 4.

61 Hakola, Rhetoric of Modern Death, 10

62 William Patrick Day, Vampire Legends in

Contemporary American Culture: What Becomes a

Legend Most (Kentucky: Kentucky UP, 2015), 4.

63 Gelder, Reading the Vampire, 141.

64 Hallab, Vampire God, 3.

65 Bell, American Vampires; Richard Blum and

Eva Blum, The Dangerous Hour: The Lore of Crisis

and Mystery in Rural Greece (New York: Charles
Scribner's Sons, 1970).

66 Day, Vampire Legends, 12.

67 Hakola, Rhetoric of Modern Death.

68 lbid., 3.

69 Cheng et al, "Suicide Contagion": 7

70 ibid.

71 Frazer, Golden Bough.

FM Heidi S. Kosonen toimii väitöskirjatutkijana Jyväskylän yliopiston musiikin, taiteen ja kulttuurin tutkimuksen laitoksella. Hän viimeistelee tabua käsittelevää väitöskirjaa, jonka tarkastelun kohteena on erityises-

ti seksuaalisuuteen ja kuolemaan kohdistuvan biovallan ilmeneminen jälkimodernissa kuvakulttuurissa. Erityisesti itsemurhan visuaalisia representaatioita Kosonen on tarkastellut etnologiatieteisiin laatimastaan kandidaatintutkielmasta (2007-2008) lähtien. Vapaa-ajallaan Kosonen muun muassa ylläpitää tutkimusblogia osoitteessa: https://theoryoftaboo. wordpress.com/ 